\title{
Concept and utility of population pharmacokinetic and pharmacokinetic/ pharmacodynamic models in drug development and clinical practice
}

\author{
Maša Roganović ${ }^{1 *}$, Ana Homšek ${ }^{1 *}$, Marija Jovanovićc ${ }^{1 \#,}$ \\ Valentina Topić Vučenović², Milica Ćulafić1, Branislava Miljković1, \\ Katarina Vučićević ${ }^{1}$
}

\author{
${ }^{1}$ University of Belgrade -Faculty of Pharmacy, Department of Pharmacokinetic and \\ Clinical Pharmacy, Vojvode Stepe 450, 11221 Belgrade, Serbia \\ ${ }^{2}$ University of Banja Luka - Faculty of Medicine, Save Mrkalja 14, 78000 Banja Luka, \\ Bosnia and Herzegovina
}

\begin{abstract}
*These authors contributed equally to the manuscript and share the first authorship
\#Corresponding author, Marija Jovanović, e-mail: marijaj@pharmacy.bg.ac.rs
\end{abstract}

\begin{abstract}
Due to frequent clinical trial failures and consequently fewer new drug approvals, the need for improvement in drug development has, to a certain extent, been met using model-based drug development. Pharmacometrics is a part of pharmacology that quantifies drug behaviour, treatment response and disease progression based on different models (pharmacokinetic - PK, pharmacodynamic - PD, PK/PD models, etc.) and simulations. Regulatory bodies (European Medicines Agency, Food and Drug Administration) encourage the use of modelling and simulations to facilitate decision-making throughout all drug development phases. Moreover, the identification of factors that contribute to variability provides a basis for dose individualisation in routine clinical practice. This review summarises current knowledge regarding the application of pharmacometrics in drug development and clinical practice with emphasis on the population modelling approach.
\end{abstract}

Keywords: pharmacometrics, population analysis, pharmacokinetics, pharmacokinetic-pharmacodynamic modelling

doi.org/10.5937/arhfarm71-32901 


\section{Introduction}

Drug development encompasses a series of activities which include choosing a drug candidate among many potential compounds, preclinical and clinical research followed by the approval of the final product for marketing by the corresponding regulatory bodies and post-marketing surveillance (Figure 1) $(1,2)$. The goal of clinical trials is to obtain the clinical data to enable product labelling, which ultimately provides information to healthcare professionals and patients regarding drug efficacy and safety (1). The common path of clinical trials includes four phases: phase I - safety, tolerability and clinical pharmacology to support the trial; phase IIa - preliminary safety and efficacy; phase IIb - confirmation of efficacy and dose range finding; phase III - large scale confirmation of efficacy and safety aiming to support registration; phase IV - obligatory post-marketing surveillance (1). The greatest challenge in "first-in-human" studies is to determine the dose to be given, as well as the dosage form. Phase II studies have the lowest success rate out of all drug development phases and since they are exploratory in their nature, the obtained data could be misused in clinical practice (3). Since rare adverse reactions cannot be detected in phase III due to limited statistical power, duration of the trial phase and number of patients, the final phase IV further investigates treatment safety on a larger number of patients over a longer period of time and confirms the efficacy using clinical endpoints by performing mortality/morbidity and epidemiological studies $(3,4)$.

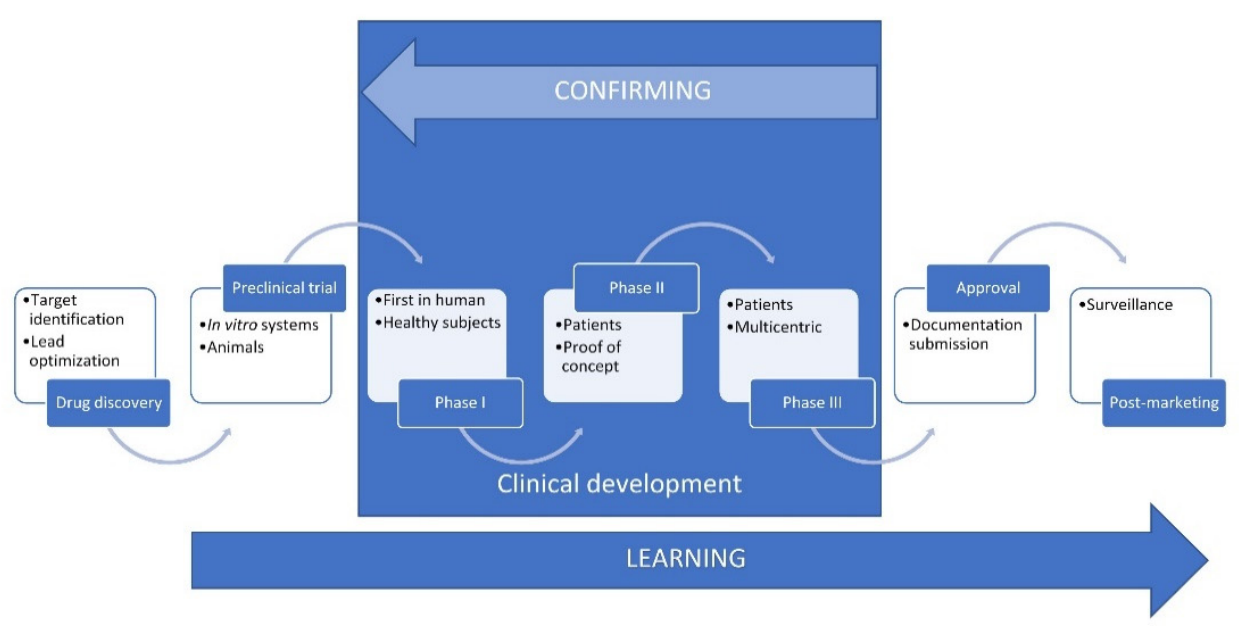

Figure 1. Drug development stages

Slika 1. Faze razvoja leka

More frequent late phase failures, fewer approvals of new drugs, expiring patents and stricter price control from financiers lead to problems in research and development of new products (5). The main causes of clinical trial failures are considered to be: inadequate exposure-response characterization, lack of efficacy data in the target 
population, partial knowledge regarding the drug and indication of interest due to inadequate data collection, suboptimal determination of the primary endpoints, data analysis and interpretation (6).

Therefore, model-based drug development (MBDD) has been suggested to improve the success rate of new drug development and clinical trials in general. This approach provides better insight into the drug candidate behaviour and ensures facilitated decisionmaking (5). Food and Drug Administration (FDA) has established the "Critical Path Initiative," a document which suggested the usage of a MBDD, where pharmacometrics is believed to play a critical role (7). Indeed, many articles confirm the importance of using pharmacometric analysis in more informed regulatory decisions (8-11). In addition, several regulatory guidelines and documents have been issued (12-16).

Pharmacometrics is applied to quantify drug, disease and trial characteristics to support not only drug development and regulatory decisions, but also rational drug treatment $(10,17)$. Hence, this review aims to provide an overview of the application of pharmacometric analysis, focusing on the drug model and population approach. More information about disease progression and trial models may be found elsewhere (18). In the first section, commonly used pharmacokinetic (PK), pharmacodynamic (PD) and pharmacokinetic/pharmacodynamic (PK/PD) models will be introduced, followed by the concept of population modelling approach, frequently used software packages, and a brief overview of the main steps in the population model development and simulations. In the following sections, the role of pharmacometrics in drug development and clinical practice will be presented, focusing on population modelling and simulations. The final section presents the role of population modelling in special population.

\section{Pharmacometric analysis approach}

Pharmacometrics uses mathematical models based on pharmacology, physiology and disease to describe and quantify interactions between drugs and patients (19-21). It is primarily based on modelling and simulation of data, which includes, but is not limited to, PK, PD, and PK/PD modelling with a focus on population and variability $(21,22)$. Pharmacometrics is an evolving science that continuously improves and encompasses or connects other disciplines. Methodologies such as the physiologically-based pharmacokinetic (PBPK) modelling approach and quantitative systems pharmacology have recently gained much broader applications in drug development (21).

\section{Type of PK and PK/PD models}

PK models describe how drug concentration in the body changes over time. Compartmental modelling is the most frequently used approach, in which the body is represented as a system of connected but separate compartments. A compartment is a group of tissues or organs with a similar blood flow and affinity for the drug. Models usually include a central compartment representing where the concentration is measured (e.g., plasma), with one or more peripheral compartments into which drugs may distribute $(21,23,24)$. In contrast to PBPK models, compartmental models are mainly empirical 
descriptions of the observed data, without such mechanistic elements $(21,23)$. Combining the classical compartment model and statistical principles led to the development of the population PK modelling analysis.

PD models describe the relationship between drug concentrations and drug effect. PK/PD models link dose and PK information to certain measures of activity and clinical outcomes. Beside treatment efficacy assessment, drug safety profile may be characterised as well $(21,24,25)$. Common concentration-effect models for continuous PD metrics include linear, log-linear, maximum effect (Emax), and sigmoidal $E_{\max }$ models $(21,24-26)$. An example of the relationship between PK and PD is presented at Figure $2(23,26)$. Drug concentration in the central compartment may be directly linked to the effect (direct effect), or there may be a time delay due to a biophase equilibration (effect compartment model) or the need to develop a response (indirect response model) $(21,25,26)$. Moreover, transit compartment models and the development of tolerance may be included $(21,25)$. Models describing discrete PD effects usually use logistic equations to convert the effect to a probability $(21,24,25)$, or time to event analysis including single or multiple events (27).

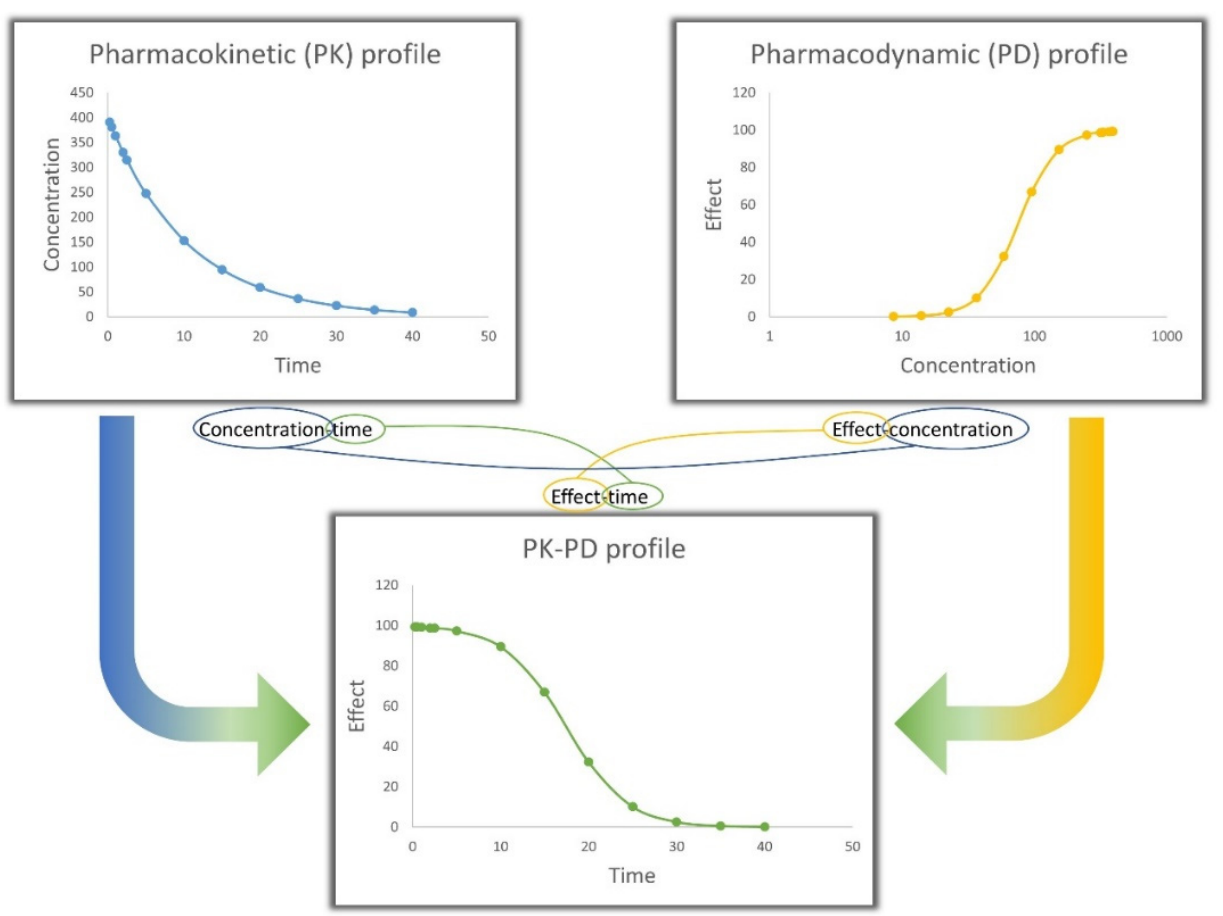

Figure 2. Pharmacokinetic (PK), pharmacodynamic (PD) and PKPD models Slika 2. Farmakokinetički (FK), farmakodinamički (FD) i FKFD modeli 


\section{Population pharmacometric analysis methodology}

Population PK can be defined as a study of variability in drug concentrations among individuals $(12,28)$. Over the past few decades, a variety of modelling methods have been proposed $(29,30)$. The concept of population PK, based on non-linear mixed effects (NLME) approach, was introduced in 1972 by Sheiner et al. (31). NLME involves the simultaneous estimation of the typical and variance parameters using data of the entire population (30). Initially developed to analyse sparse PK data, this approach was later expanded to include PD models (24). Nowadays, this methodology represents a golden standard for population analysis, and the terms are often used as synonyms $(24,30)$. It is widely used because of the ability to quantify several variability levels, handle sparse, unbalanced and fragmentary data, and identify influential covariates (14, 24, 30, 32-34). Hence, available software and modelling aspects of NLME are described in more details in the following text.

NONMEM was the first software package developed for population modelling analysis, realised in the early 1980s (35). Subsequently, other software packages have been developed, such as Monolix (36), Phoenix NLME (37), various packages in R (38), and many more. Most of the software applies parametric maximum likelihood estimation, but other approaches are also available (39).

The development of a population $\mathrm{PK}$ or $\mathrm{PK} / \mathrm{PD}$ model includes several steps defined in the pharmacometric analysis plan $(12,21,40,41)$. To better understand the data and guide model development, exploratory analysis is recommended, including various graphical and numerical methods $(21,40,41)$.

In the initial step, the structural and statistical model ought to be developed. The structural model describes the PK and PD characteristics for a typical subject (e.g. onecompartment with lag time, or sigmoidal $E_{\max }$ model) $(21,24,25,33)$. Fixed-effect parameters are structural parameters that describe drug behaviour in a typical subject. Certain covariates may be included as a part of this base model only if a good rationale exists $(40,41)$. Statistical (stochastic) models describe the unexplained variability (random effects) in the observed data $(24,25,42)$. In contrast to the classical approach, population models may distinguish between-subject (variability of a parameter across individuals) and residual variability (the difference between the observed data and the model predictions). Models may also include, where relevant, between-occasional variability, usually observed in drugs used in oncology treatments $(24,25,42,43)$. The next step includes covariate model development aiming to explain the variability and describe the influence of intrinsic and extrinsic factors (covariates) on model parameters (24). Covariates are subject-specific factors such as demographics (body weight, age, gender, race), physiologic and pathophysiologic characteristics, biochemical laboratory parameters' values, genetic polymorphism, co-medications, and environmental factors (e.g., smoking, alcohol intake) that may impact PK and/or PD variability (43). Among several methods in covariates evaluation $(40,41)$, stepwise covariate model (SCM) building approach is the most frequently used (44). Besides statistical significance, the 
clinical relevance of candidate covariates should be considered. After assessing and retaining all the relevant covariates, model may be regarded as final $(21,40)$.

Model diagnostics are performed during each of the key steps of the process, including the validation of the final model (40). Ultimately, the evaluation and qualification confirms the adequacy of data description by the model regarding its behaviour and proposed purpose (21). Among many diagnostic tools and validation techniques $(34,41,42,45,46)$, the most appropriate one should be chosen depending on the type of data and the purpose of the model (descriptive or predictive) $(12,42,47)$. In general, a combination of several methods is preferred so that the relative strengths and shortcomings of each approach can complement each other (14).

Pharmacometric models could be used for simulation studies, where they could be useful for predicting different clinical scenarios not accounted for by the study design, such as different dosage regimens or other patient populations. Generally, stochastic simulations using a mixed effect model are more complex than non-stochastic simulations based on a model with fixed effects $(21,24)$. Depending on the purpose of the simulation, the variability and parameter uncertainty should be considered $(14,21)$. Finally, the results of any modelling and simulation analysis should be appropriately reported $(12,21$, $40,41)$.

\section{Role of population pharmacometric approach in drug development}

Pharmacometrics can be used in every phase of drug development, from molecule screening to post-marketing surveillance. Both clinical and nonclinical decisions are made with the support of pharmacometrics: go/no-go decisions, dosage range, end points, trial timing, trial design development, etc (23). However, the population modelling approach is primarily used in clinical development, while its application in preclinical phase is still limited. Nevertheless, population analysis can be utilised in this stage to summarise the PK data and $\mathrm{PK} / \mathrm{PD}$ relationships obtained from different animal groups or species, predict parameter values in humans, optimise subsequent trial designs, and reduce the time from new drug discovery to clinical trials (48-50). For instance, compartmental modelling in allometric scaling-up can be performed by population $\mathrm{PK}$ in addition to the classical approach (50).

\section{Clinical drug development}

Design inefficiencies, inadequate efficacy and safety outcomes, blood sampling schemes, and clinical trial failures can be avoided by incorporating disease drug trial models and clinical trial simulations $(22,51)$. Simulations can predict essential data regarding drug behaviour after repeated drug administration, potential drug interactions and their impact on PK/PD profiles, the influence of hepatic/renal failure, and the dose required to achieve target concentration. They can also be useful in estimating the sample size and choosing the adequate statistical test to obtain the greatest power (52). The success rate of clinical trials is improved by studying the impact of protocol deviations, which is performed by answering the "what-if" questions $(52,53)$. 
The rationale for using modelling in phase I of clinical trials lies in the possibility of estimating PK and PD parameters of the population, dosage regimen optimisation, selection of the most efficacious sampling and combined data analysis $(24,54)$. Subsequent clinical trial phases incorporate population models in order to characterise therapeutic index, food effects, drug-drug and drug-disease interactions, exposureresponse relationship, clinical and patient variability factors, benefit-risk ratio and contribute to various regulatory decisions $(22,23,55)$. Before each new clinical trial phase, design optimisation is performed by simulating possible outcomes and analysing the available data. In the final pre-approval stage of clinical development, modelling and simulation can offer additional recommendations regarding patient-specific dose adjustment, new indications, bridging studies and post-marketing study design. Selecting the best possible biomarker and its target value for optimal response is one of the critical assignments of this approach. Even the drug effect parameter of a PK/PD model has been suggested as a good substitution for clinical trial endpoint (56).

The abbreviated approval pathway for biosimilars differs from the pathway for generic drugs. Population modelling is used to acquire the doses for PK and PK/PD similarity studies, improve the design of the study based on interindividual variability, verify PD biomarkers and compare different administration routes to approve new formulations (57). Model-based simulations are convenient to demonstrate the doseexposure relationship of drugs with nonlinear PK, which is common among biologic drugs, mostly due to target-mediated drug disposition (58).

\section{Regulatory aspects}

With a growing interest in pharmacometrics, the need for the development of appropriate guidelines has been recognised by regulatory agencies. The European medicines agency (EMA) and FDA provide guidance files on the use of on population PK analyses $(12,14)$. While EMA shifts the focus of the guidance file to analysis plan and more detailed information regarding result report, FDA provides methodological aspects and information about data used for population PK analysis. Additionally, EMA has issued guidelines for different special populations on the role of PK in the development of medicinal products. The guideline for the paediatric population summarises the use of PK and PK/PD relationships in efficacy and safety evaluations, study design and data analysis, suggesting population PK analysis as an appropriate methodology for practical and ethical reasons (59). Moreover, the FDA guideline for exposure-response relationship highlights the usefulness of population PK analysis combined with the Bayesian method when analysing sparse data, which is often the case in paediatric or geriatric populations (16). The goal of these regulatory initiatives is to support the use of pharmacometrics throughout all drug development stages and encourage pharmaceutical industry to implement it in their research and development, reduce costs, save time and improve success rates. 


\section{Post-marketing research and application in routine clinical practice}

\section{Post-marketing research and lifecycle management}

The main goal of phase IV or post-marketing surveillance studies is to verify the effectiveness and safety of the drug in a real life conditions (60). Contrary to the premarketing trials, these studies include a larger number of patients and more heterogeneous population in the terms of age, gender, comorbidities, concomitant therapy and genotype (61). Such clinical trial settings, empowered by the population approach methodology in data analysis, enable the identification of factors not detected in the previous phases of the clinical trial that contribute significantly to variability in drug exposure and response (23). Thus, relevant information about drug-drug interactions, drug-disease interactions and the influence of other factors can be characterised in real life conditions (23). Furthermore, the population PK approach is useful when analysing sparse data, which is often the case in routine clinical practise and during therapeutic drug monitoring (TDM). For instance, numerous population PK models for antiepileptic drugs were created, even though the number of blood samples was limited (62-66). Similarly, the utility of population PK approach could be observed in characterising immunosuppressive drugs' PK. Golubovic et al. developed population PK models based on TDM data of sirolimus and tacrolimus from adult kidney transplant patients $(67,68)$. Moreover, the published population models and intrinsic and extrinsic factors contributing to variability for specific therapeutic groups are summarised in review articles $(69,70)$.

Additionally, the advantages of modelling are reflected in its ability to integrate data from different stages of drug development - preclinical, clinical and post-marketing surveillance studies, which facilitates further investigations of the drug PK and PD in different populations of patients (23). Furthermore, population PK analysis facilitates the determination of dosing regimen for some off-label drugs (56) and new formulation development (23).

\section{Dose individualisation}

Besides having a substantial role in drug research and development, pharmacometrics has an increasing impact on routine clinical practice in healthcare systems. In the centre of each healthcare system is a patient with his/her specific, individual characteristics to whom a drug, in a certain dosage regimen, is prescribed. Usually, the dose prescribed is the same for every patient (71). However, for some drugs, the response to the usual dosage regimen is often different between patients and sometimes can even vary within the individual patient. Such an unexpected response to drug therapy can result in treatment failure. These consequences are reflected in disease progression and/or occurrence of adverse effects, which leads to decreased quality of life in patients and additional expenses of health-care systems $(72,73)$. Therefore, identifying and quantifying the sources of PK and/or PD variability is the cornerstone of therapy individualisation $(74,75)$. Although TDM is one of the oldest tools used to optimise dosage regimen, this approach, when used independently, is insufficiently informative 
when it comes to dosing optimisation recommendations. The main flaw of traditional TDM is the existence of a reference range of concentrations instead of one target concentration, which means that a clinician's decision making is driven by experience, rather than evidence-based facts $(71,76)$. Moreover, samples should be taken from patients after steady state is achieved (77). One way to overcome the disadvantages of classical TDM is to use approaches that take into account the drug, disease, and patient characteristics, such as the model informed drug precision approach (MIPD) (78). In this approach, TDM data, together with the individual patient's demographic, pharmacogenetic, clinical and therapy characteristics, are interpreted using the population model $(31,77,79)$. Even before the administration of the first dose, the developed model can be used to calculate population parameters considering covariates for the specific patient and propose dosage regimen based on these estimates. When measured drug concentrations become available, the patient's parameters can be estimated through socalled Bayesian forecasting (80). It uses prior information about population model parameters and their uncertainties together with measured drug concentrations and individual covariates to maximize the probability of individual parameter values (maximum a posteriori Bayesian estimate). Consequently, the estimated individual parameters are further used for more precise dosage regimen optimisation $(56,77,81)$. Moreover, simulations can be performed based on the individual PK parameters, to obtain a dosing regimen that maximizes the achievement of the target (77). Due to the complexity of NONMEM software in routine clinical practice, new tools are being developed (82). Currently, around 28 software tools based on MIPD are available for research and/or clinical purposes, and approximately half are using the Bayesian approach (83). At the moment, the majority of the software is intended for optimal dose selection for antibiotics, as appropriate dosing is essential from the beginning of the therapy (78, 80,83 ). A confirmation of the utility of MIPD in dose selection and optimisation has recently been published in the Consensus guidelines on TDM of vancomycin. The guideline suggests that Bayesian based software programs are a preferable tool for dosing regimen creation/adjustment in order to achieve the target value of area under the curve (84). However, regardless of the numerous advantages of Bayesian-based software programs, some challenges need to be resolved before their implementation in routine clinical practice $(80,82)$. Another tool for dosing individualisation that can be used together with the PK/PD models or Bayesian approach is target concentration intervention. Its use requires target concentration/biomarker and estimated values of key PK and/or PD parameters for the calculation of loading and maintenance dose. After the calculated doses are given to the patient, the drug concentration or response is measured again and used as feedback in the decision making process $(71,76)$.

\section{Special populations}

Patients younger than 18 years (paediatrics), older than 65 years (elderly), women (pregnant or non-pregnant), or patients with certain diseases (kidney/liver function/gastrointestinal tract, rare diseases), and critically ill patients are considered 
special populations $(85,86)$. Usually, these patients are excluded from clinical trials due to their vulnerability, ethical reasons, and strict regulation laws $(85,87)$. Nevertheless, a practitioner needs to prescribe a drug in an appropriate dosing regimen to these patients, having in mind the factors that differentiate special population patients from the general population of adults. Using identical dosing regimens in patients that belong to a special population can result in either a lack of drug efficacy, or drug toxicity, as a consequence of changed physiology (pathophysiology), and consequently the drug's behaviour (85, 87).

Including special populations in clinical trials requires certain modifications of the typical study design. The most apparent one is a limited number of participants and sparse data sampling, which could be adequately handled only by the modelling and simulation approaches $(87,88)$. Hence, dosing recommendations for special populations may be obtained, and sometimes simulation studies can even substitute clinical trials in the mentioned groups $(14,23)$. Children go through developmental changes in terms of body size/body composition and organ function (89), which is especially important in infants (90). The influence of developmental changes can be assessed by using size and/or age as covariates in population analysis $(32,91)$. One approach used to describe midazolam clearance in critically ill children is based on allometric scaling combined with sigmoidal maturation function (92). On the other hand, in older critically ill patients, the reduction of elimination organ function should be accounted for. Hence, the developed population model of vancomycin explains the impact of creatinine clearance on drug elimination, indicating that renal function should be considered for dosing regimen optimisation (93).

The possibility of predicting the optimal dosing regimen in vulnerable populations in order to achieve target exposure can be seen in study by Wallender et al. (94), where the authors proposed an alternative dosage regimen of an antimalaric drug for pregnant, HIV infected women ensuring safe and effective prophylaxis.

Finally, the application of PBPK modelling approach has been continuously increasing over the past several years (95). PBPK models use population-specific physiologic parameters, drug-specific physicochemical and PK information as input parameters in modelling process, in order to predict drug disposition in various populations $(96,97)$. Considering the mechanistic nature and the possibility of integrating population-specific physiologic changes, PBPK may be useful for a variety of purposes in specific populations and especially in assessing drug-drug interactions $(95,97)$. Regarding children younger than 2 years, it has been even debated whether this approach may be preferred over allometric-scaling (95). In general, the use of PBPK models in drug development is supported in regulatory documents (98-100).

\section{Conclusion}

Population analysis, as an integral part of pharmacometrics, has a wide range of applications in drug development and direct patient care. The process of model development and evaluation depends on the purpose of the model. Population analysis may simply be conducted to describe the available data. On the other hand, predictive 
population analysis allows simulations that can be used to answer "what-if" questions. A special case of predictive population analysis is the utilisation of the developed model to design a future clinical trial. Finally, the identification of the influential covariates provides a basis for dose individualisation in routine clinical practice.

\section{Acknowledgement}

This work was supported by the Ministry of Education, Science and Technological Development, Belgrade, Republic of Serbia [Grant No. 451-03-9/2021-14/200161].

\section{Conflicts of interest}

The authors declare that they have no conflict of interest.

\section{References}

1. Hill RG. Drug discovery and development: Technology in transition: Elsevier Health Sciences; 2012.

2. Turner JR. New drug development: An introduction to clinical trials. New York: Springer; 2010.

3. Salazar DE, Gormley G. Modern drug discovery and development. In: Robertson D, Williams G, editors. Clinical and translational science: Principles of human research. London: Elsevier; 2017. p. 719-43.

4. Marchenko OV, Katenka NV. Quantitative methods in pharmaceutical research and development: Concepts and applications: Springer; 2020.

5. Kimko H, Pinheiro J. Model-based clinical drug development in the past, present and future: A commentary. Br J Clin Pharmacol. 2015;79(1):108-16.

6. Milligan PA, Brown MJ, Marchant B, Martin SW, van der Graaf PH, Benson N, et al. Model-based drug development: A rational approach to efficiently accelerate drug development. Clin Pharmacol Ther. 2013;93(6):502-14.

7. U.S. Food and Drug Administration. Innovation or stagnation: Challenge and opportunity on the critical path to new medical products 2004. Available from: https://www.fda.gov/scienceresearch/science-and-research-special-topics/critical-path-initiative.

8. Bhattaram VA, Bonapace C, Chilukuri DM, Duan JZ, Garnett C, Gobburu JV, et al. Impact of pharmacometric reviews on new drug approval and labeling decisions-a survey of 31 new drug applications submitted between 2005 and 2006. Clin Pharmacol Ther. 2007;81(2):213-21.

9. Bhattaram VA, Booth BP, Ramchandani RP, Beasley BN, Wang Y, Tandon V, et al. Impact of pharmacometrics on drug approval and labeling decisions: A survey of 42 new drug applications. AAPS J. 2005;7(3):E503-12. 
10. Lee JY, Garnett CE, Gobburu JV, Bhattaram VA, Brar S, Earp JC, et al. Impact of pharmacometric analyses on new drug approval and labelling decisions: A review of 198 submissions between 2000 and 2008. Clin Pharmacokinet. 2011;50(10):627-35.

11. Wang Y, Bhattaram AV, Jadhav PR, Lesko LJ, Madabushi R, Powell JR, et al. Leveraging prior quantitative knowledge to guide drug development decisions and regulatory science recommendations: Impact of FDA pharmacometrics during 2004-2006. J Clin Pharmacol. 2008;48(2):146-56.

12. European Medicines Agency. Guideline on reporting the results of population pharmacokinetic analyses 2007. Available from: https://www.ema.europa.eu/en/reporting-results-populationpharmacokinetic-analyses.

13. U.S. Food and Drug Administration. Guidance for industry population pharmacokinetics 1999. Available from: https://www.fda.gov/media/71364/download.

14. U.S. Food and Drug Administration. Population pharmacokinetics guidance for industry; draft guidance 2019. Available from: https://www.fda.gov/regulatory-information/search-fda-guidancedocuments/population-pharmacokinetics.

15. EFPIA MID3 Workgroup, Marshall SF, Burghaus R, Cosson V, Cheung SY, Chenel M, et al. Good practices in model-informed drug discovery and development: Practice, application, and documentation. CPT Pharmacometrics Syst Pharmacol. 2016;5(3):93-122.

16. U.S. Food and Drug Administration. Exposure-response relationships - study design, data analysis, and regulatory applications 2003. Available from: https://www.fda.gov/regulatoryinformation/search-fda-guidance-documents/exposure-response-relationships-study-design-dataanalysis-and-regulatory-applications.

17. Gobburu JV. Pharmacometrics 2020. J Clin Pharmacol. 2010;50(9 Suppl):151S-7S.

18. Gobburu JV, Lesko LJ. Quantitative disease, drug, and trial models. Annu Rev Pharmacol Toxicol. 2009;49:291-301.

19. Barrett JS, Fossler MJ, Cadieu KD, Gastonguay MR. Pharmacometrics: A multidisciplinary field to facilitate critical thinking in drug development and translational research settings. J Clin Pharmacol. 2008;48(5):632-49.

20. Ette EI, Williams PJ. Pharmacometrics: The science of quantitative pharmacology. Hoboken: Wiley; 2007.

21. Xu Y, Kimko H. Pharmacometrics: A quantitative decision-making tool in drug development. In: Marchenko O, Katenka N, editors. Quantitative methods in pharmaceutical research and development. 1 ed: Springer; 2020. p. 71-104.

22. Lala M, Gobburu JV. Pharmacometrics: Concepts and applications to drug development. In: Kaplan B, Burckart GJ, Lakkis FG, editors. Immunotherapy in transplantation: Principles and practice. 1 ed: Wiley-Blackwell; 2012. p. 114-32.

23. Kim TH, Shin S, Shin BS. Model-based drug development: Application of modeling and simulation in drug development. J Pharm Investig. 2018;48(4):431-41.

24. Mould DR, Upton RN. Basic concepts in population modeling, simulation, and model-based drug development. CPT Pharmacometrics Syst Pharmacol. 2012;1(9):e6.

25. Upton RN, Mould DR. Basic concepts in population modeling, simulation, and model-based drug development: Part 3-introduction to pharmacodynamic modeling methods. CPT Pharmacometrics Syst Pharmacol. 2014;3:e88. 
26. Derendorf H, Meibohm B. Modeling of pharmacokinetic/pharmacodynamic (PK/PD) relationships: Concepts and perspectives. Pharm Res. 1999;16(2):176-85.

27. Holford N. A time to event tutorial for pharmacometricians. CPT Pharmacometrics Syst Pharmacol. 2013;2:e43.

28. Aarons L. Population pharmacokinetics: Theory and practice. Br J Clin Pharmacol. 1991;32(6):669-70.

29. Ette EI, Williams PJ. Population pharmacokinetics II: Estimation methods. Ann Pharmacother. 2004;38(11):1907-15.

30. Kiang TK, Sherwin CM, Spigarelli MG, Ensom MH. Fundamentals of population pharmacokinetic modelling: Modelling and software. Clin Pharmacokinet. 2012;51(8):515-25.

31. Sheiner LB, Rosenberg B, Melmon KL. Modelling of individual pharmacokinetics for computeraided drug dosage. Comput Biomed Res. 1972;5(5):411-59.

32. De Cock RF, Piana C, Krekels EH, Danhof M, Allegaert K, Knibbe CA. The role of population PKPD modelling in paediatric clinical research. Eur J Clin Pharmacol. 2011;67 Suppl 1:5-16.

33. Duffull SB, Wright DF, Winter HR. Interpreting population pharmacokinetic-pharmacodynamic analyses - a clinical viewpoint. Br J Clin Pharmacol. 2011;71(6):807-14.

34. Nguyen TH, Mouksassi MS, Holford N, Al-Huniti N, Freedman I, Hooker AC, et al. Model evaluation of continuous data pharmacometric models: Metrics and graphics. CPT Pharmacometrics Syst Pharmacol. 2017;6(2):87-109.

35. Beal S SL, Boeckmann A, Bauer RJ. Nonmem user's guides. Ellicott City: Icon Development Solutions; 1989-2018.

36. Monolix. 2020R1 version: Lixoft. Available from: https://lixoft.com/products/monolix/

37. Phoenix NLME. 8.3 version: Certara. Available from: https://www.certara.com/software/pkpdmodeling-and-simulation/phoenix-nlme/

38. The R project for statistical computing. R Core Team. Available from: https://www.r-project.org/

39. Pillai GC, Mentre F, Steimer JL. Non-linear mixed effects modeling - from methodology and software development to driving implementation in drug development science. J Pharmacokinet Pharmacodyn. 2005;32(2):161-83.

40. Byon W, Smith MK, Chan P, Tortorici MA, Riley S, Dai H, et al. Establishing best practices and guidance in population modeling: An experience with an internal population pharmacokinetic analysis guidance. CPT Pharmacometrics Syst Pharmacol. 2013;2:e51.

41. Owen JS, Fiedler-Kelly J. Introduction to population pharmacokinetic/pharmacodynamic analysis with nonlinear mixed effects models. New Jersey: John Wiley \& Sons; 2014.

42. Mould DR, Upton RN. Basic concepts in population modeling, simulation, and model-based drug development-part 2: Introduction to pharmacokinetic modeling methods. CPT Pharmacometrics Syst Pharmacol. 2013;2:e38.

43. Ette EI, Williams PJ. Population pharmacokinetics I: Background, concepts, and models. Ann Pharmacother. 2004;38(10):1702-6.

44. Jonsson EN, Karlsson MO. Automated covariate model building within NONMEM. Pharm Res. 1998;15(9):1463-8.

45. Karlsson MO, Savic RM. Diagnosing model diagnostics. Clin Pharmacol Ther. 2007;82(1):17-20.

46. Sherwin CM, Kiang TK, Spigarelli MG, Ensom MH. Fundamentals of population pharmacokinetic modelling: Validation methods. Clin Pharmacokinet. 2012;51(9):573-90. 
47. Ette EI, Williams PJ, Lane JR. Population pharmacokinetics III: Design, analysis, and application of population pharmacokinetic studies. Ann Pharmacother. 2004;38(12):2136-44.

48. Bender G, Gosset J, Florian J, Tan K, Field M, Marshall S, et al. Population pharmacokinetic model of the pregabalin-sildenafil interaction in rats: Application of simulation to preclinical PK-PD study design. Pharm Res. 2009;26(10):2259-69.

49. Chen WJ, Zhou TY, Lu W. Population pharmacokinetics and its application in new drug research (abstract). Yao xue xue bao = Acta pharmaceutica Sinica. 2017;52(3):371-7.

50. Porzio S. Application of population pharmacokinetics for preclinical safety and efficacy studies. Bioanalysis. 2013;5(16):2053-69.

51. Holford N, Ma SC, Ploeger BA. Clinical trial simulation: A review. Clin Pharmacol Ther. 2010;88(2):166-82.

52. Bonate PL. Clinical trial simulation in drug development. Pharm Res. 2000;17(3):252-6.

53. Girard P. Clinical trial simulation: A tool for understanding study failures and preventing them. Basic Clin Pharmacol Toxicol. 2005;96(3):228-34.

54. Aarons L, Karlsson MO, Mentre F, Rombout F, Steimer JL, van Peer A, et al. Role of modelling and simulation in phase I drug development. Eur J Pharm Sci. 2001;13(2):115-22.

55. Bellanti F, van Wijk RC, Danhof M, Della Pasqua O. Integration of PKPD relationships into benefitrisk analysis. Br J Clin Pharmacol. 2015;80(5):979-91.

56. Standing JF. Understanding and applying pharmacometric modelling and simulation in clinical practice and research. Br J Clin Pharmacol. 2017;83(2):247-54.

57. Hourcade-Potelleret F, Lemenuel-Diot A, McIntyre C, Brewster M, Lum B, Bittner B. Use of a population pharmacokinetic approach for the clinical development of a fixed-dose subcutaneous formulation of trastuzumab. CPT Pharmacometrics Syst Pharmacol. 2014;3:e87, doi: 10.1038/psp.2013.63.

58. Wang YC, Wang Y, Schrieber SJ, Earp J, Thway TM, Huang SM, et al. Role of modeling and simulation in the development of novel and biosimilar therapeutic proteins. J Pharm Sci. 2019;108(1):73-7.

59. European Medicines Agency. Guideline on the role of pharmacokinetics in the development of medicinal products in the paediatric population. 2007. Available from: https://www.ema.europa.eu/en/documents/scientific-guideline/guideline-role-pharmacokineticsdevelopment-medicinal-products-paediatric-population_en.pdf

60. Suvarna V. Phase IV of drug development. Perspect Clin Res. 2010;1(2):57-60.

61. Farahani P, Levine M, Gaebel K, Thabane L. Clinical data gap between phase III clinical trials (premarketing) and phase IV (post-marketing) studies: Evaluation of etanercept in rheumatoid arthritis. Can J Clin Pharmacol. 2005;12(3):e254-63.

62. Brzakovic B, Vucicevic K, Kovacevic SV, Miljkovic B, Prostran M, Martinovic Z, et al. Pharmacokinetics of lamotrigine in paediatric and young adult epileptic patients-nonlinear mixed effects modelling approach. Eur J Clin Pharmacol. 2014;70(2):179-85.

63. Jovanovic M, Sokic D, Grabnar I, Vovk T, Prostran M, Vucicevic K, et al. Population pharmacokinetics of topiramate in adult patients with epilepsy using nonlinear mixed effects modelling. Eur J Pharm Sci. 2013;50(3-4):282-9. 
64. Vucicevic K, Jovanovic M, Golubovic B, Kovacevic SV, Miljkovic B, Martinovic Z, et al. Nonlinear mixed effects modelling approach in investigating phenobarbital pharmacokinetic interactions in epileptic patients. Eur J Clin Pharmacol. 2015;71(2):183-90.

65. Vucicevic K, Miljkovic B, Pokrajac M, Prostran M, Martinovic Z, Grabnar I. The influence of drugdrug interaction and patients' characteristics on valproic acid's clearance in adults with epilepsy using nonlinear mixed effects modeling. Eur J Pharm Sci. 2009;38(5):512-8.

66. Vucicevic K, Miljkovic B, Velickovic R, Pokrajac M, Mrhar A, Grabnar I. Population pharmacokinetic model of carbamazepine derived from routine therapeutic drug monitoring data. Ther Drug Monit. 2007;29(6):781-8.

67. Golubovic B, Vucicevic K, Radivojevic D, Kovacevic SV, Prostran M, Miljkovic B. Total plasma protein effect on tacrolimus elimination in kidney transplant patients-population pharmacokinetic approach. Eur J Pharm Sci. 2014;52:34-40.

68. Golubovic B, Vucicevic K, Radivojevic D, Kovacevic SV, Prostran M, Miljkovic B. Exploring sirolimus pharmacokinetic variability using data available from the routine clinical care of renal transplant patients - population pharmacokinetic approach. J Med Biochem. 2019;38(3):323-31.

69. Golubovic B, Prostran M, Miljkovic B, Vucicevic K, Radivojevic D, Grabnar I. Population pharmacokinetic approach of immunosuppressive therapy in kidney transplant patients. Curr Med Chem. 2016;23(19):1998-2011.

70. Jovanović M, Vučićević K, Miljković B. Understanding variability in the pharmacokinetics of atypical antipsychotics-focus on clozapine, olanzapine and aripiprazole population models. Drug Metab Rev. 2020;52(1):1-18.

71. Holford N. Pharmacodynamic principles and target concentration intervention. Transl Clin Pharmacol. 2018;26(4):150-4.

72. Darwich AS, Polasek TM, Aronson JK, Ogungbenro K, Wright DFB, Achour B, et al. Modelinformed precision dosing: Background, requirements, validation, implementation, and forward trajectory of individualizing drug therapy. Annu Rev Pharmacol Toxicol. 2021;61:225-45.

73. Polasek TM, Shakib S, Rostami-Hodjegan A. Precision dosing in clinical medicine: Present and future. Expert Rev Clin Pharmacol. 2018;11(8):743-6.

74. Polasek TM, Kirkpatrick CM, Rostami-Hodjegan A. Precision dosing to avoid adverse drug reactions. Ther Adv Drug Saf. 2019; 10:2042098619894147, doi: 10.1177/2042098619894147.

75. Wright DFB, Martin JH, Cremers S. Spotlight commentary: Model-informed precision dosing must demonstrate improved patient outcomes. Br J Clin Pharmacol. 2019;85(10):2238-40.

76. Holford N, Ma G, Metz D. TDM is dead. Long live TCI! Br J Clin Pharmacol. 2020; doi: 10.1111/bcp.14434.

77. Wicha SG, Martson AG, Nielsen EI, Koch BCP, Friberg LE, Alffenaar JW, et al. From therapeutic drug monitoring to model-informed precision dosing for antibiotics. Clin Pharmacol Ther. 2021;109(4):928-41.

78. Abdulla A, Edwina AE, Flint RB, Allegaert K, Wildschut ED, Koch BCP, et al. Model-informed precision dosing of antibiotics in pediatric patients: A narrative review. Front Pediatr. 2021;9:624639.

79. Charles B. Population pharmacokinetics: An overview. Australian Prescriber. 2014;37(6):210-3. 
80. Uster DW, Stocker SL, Carland JE, Brett J, Marriott DJE, Day RO, et al. A model averaging/selection approach improves the predictive performance of model-informed precision dosing: Vancomycin as a case study. Clin Pharmacol Ther. 2021;109(1):175-83.

81. Sime FB, Roberts MS, Roberts JA. Optimization of dosing regimens and dosing in special populations. Clin Microbiol Infect. 2015;21(10):886-93.

82. Keizer RJ, Ter Heine R, Frymoyer A, Lesko LJ, Mangat R, Goswami S. Model-informed precision dosing at the bedside: Scientific challenges and opportunities. CPT Pharmacometrics Syst Pharmacol. 2018;7(12):785-7.

83. Kantasiripitak W, Van Daele R, Gijsen M, Ferrante M, Spriet I, Dreesen E. Software tools for modelinformed precision dosing: How well do they satisfy the needs? Front Pharmacol. 2020;11:620.

84. Rybak MJ, Le J, Lodise T, Levine D, Bradley J, Liu C, et al. Executive summary: Therapeutic monitoring of vancomycin for serious methicillin-resistant Staphylococcus aureus infections: A revised consensus guideline and review of the American Society of Health-System Pharmacists, the Infectious Diseases Society of America, the Pediatric Infectious Diseases Society, and the Society of Infectious Diseases Pharmacists. J Pediatric Infect Dis Soc. 2020;9(3):281-4.

85. Grimsrud KN, Sherwin CM, Constance JE, Tak C, Zuppa AF, Spigarelli MG, et al. Special population considerations and regulatory affairs for clinical research. Clin Res Regul Aff. 2015;32(2):47-56.

86. Stillhart C, Vucicevic K, Augustijns P, Basit AW, Batchelor H, Flanagan TR, et al. Impact of gastrointestinal physiology on drug absorption in special populations-an UNGAP review. Eur $\mathrm{J}$ Pharm Sci. 2020;147:105280.

87. Krekels EHJ, van Hasselt JGC, van den Anker JN, Allegaert K, Tibboel D, Knibbe CAJ. Evidencebased drug treatment for special patient populations through model-based approaches. Eur J Pharm Sci. 2017;109S:S22-S6.

88. Momper JD, Mulugeta Y, Burckart GJ. Failed pediatric drug development trials. Clin Pharmacol Ther. 2015;98(3):245-51.

89. Anderson BJ, Holford NH. Mechanism-based concepts of size and maturity in pharmacokinetics. Annu Rev Pharmacol Toxicol. 2008;48:303-32.

90. Holford N, Heo YA, Anderson B. A pharmacokinetic standard for babies and adults. J Pharm Sci. 2013;102(9):2941-52

91. Germovsek E, Barker CI, Sharland M, Standing JF. Scaling clearance in paediatric pharmacokinetics: All models are wrong, which are useful? Br J Clin Pharmacol. 2017;83(4):777-90.

92. Kos MK, Miksic M, Jovanovic M, Roskar R, Grosek S, Grabnar I. Maturation of midazolam clearance in critically ill children with severe bronchiolitis: A population pharmacokinetic analysis. Eur J Pharm Sci. 2020;141:105095.

93. Kovacevic T, Miljkovic B, Kovacevic P, Dragic S, Momcicevic D, Avram S, et al. Population pharmacokinetic model of vancomycin based on therapeutic drug monitoring data in critically ill septic patients. J Crit Care. 2020;55:116-21.

94. Wallender E, Vucicevic K, Jagannathan P, Huang L, Natureeba P, Kakuru A, et al. Predicting optimal dihydroartemisinin-piperaquine regimens to prevent malaria during pregnancy for human immunodeficiency virus-infected women receiving efavirenz. J Infect Dis. 2018;217(6):964-72. 
95. Grimstein M, Yang Y, Zhang X, Grillo J, Huang SM, Zineh I, et al. Physiologically based pharmacokinetic modeling in regulatory science: An update from the U.S. Food and Drug Administration's office of Clinical Pharmacology. J Pharm Sci. 2019;108(1):21-5.

96. Jones HM, Gardner IB, Watson KJ. Modelling and PBPK simulation in drug discovery. AAPS J. 2009;11(1):155-66.

97. Huang W, Nakano M, Sager J, Ragueneau-Majlessi I, Isoherranen N. Physiologically based pharmacokinetic model of the CYP2D6 probe atomoxetine: Extrapolation to special populations and drug-drug interactions. Drug Metab Dispos. 2017;45(11):1156-65.

98. U.S. Food and Drug Administration. Physiologically based pharmacokinetic analyses - format and content guidance for industry 2018. Available from: https:/www.fda.gov/regulatoryinformation/search-fda-guidance-documents/physiologically-based-pharmacokinetic-analysesformat-and-content-guidance-industry.

99. U.S. Food and Drug Administration. In vitro drug interaction studies - cytochrome p450 enzymeand transporter-mediated drug interactions guidance for industry 2020. Available from: https://www.fda.gov/regulatory-information/search-fda-guidance-documents/vitro-druginteraction-studies-cytochrome-p450-enzyme-and-transporter-mediated-drug-interactions.

100. European Medicines Agency. Guideline on the reporting of physiologically based pharmacokinetic (PBPK) modelling and simulation 2018. Available from: https://www.ema.europa.eu/en/reportingphysiologically-based-pharmacokinetic-pbpk-modelling-simulation. 


\title{
Koncept i upotreba populacionih farmakokinetičkih i farmakokinetičko/farmakodinamičkih modela u razvoju leka i kliničkoj praksi
}

\author{
Maša Roganovići $^{* *}$, Ana Homšek ${ }^{1 *}$, Marija Jovanović ${ }^{1 \#,}$ \\ Valentina Topić Vučenović ${ }^{2}$, Milica Ćulafićc ${ }^{1}$, Branislava Miljković ${ }^{1}$, \\ Katarina Vučićevićc ${ }^{1}$
}
${ }^{1}$ Univerzitet u Beogradu - Farmaceutski fakultet, Katedra za farmakokinetiku i kliničku farmaciju, Vojvode Stepe 450, 11221 Beograd, Srbija
${ }^{2}$ Univerzitet u Banjoj Luci - Medicinski fakultet, Save Mrkalja 14, 78000 Banja Luka, Bosna and Hercegovina

*Ovi autori su podjednako doprineli radu i dele prvo autorstvo

\# Autor za korespondenciju: Marija Jovanović, e-mail: marijaj@pharmacy.bg.ac.rs

\begin{abstract}
Kratak sadržaj:
Usled čestih neuspeha u kliničkim ispitivanjima i posledično manjeg broja odobrenja novih lekova, potreba za poboljšanjem u razvoju lekova je u određenoj meri zadovoljena korišćenjem pristupa razvoja lekova zasnovanog na modelu. Farmakometrija predstavlja granu farmakologije koja kvantifikuje ponašanje leka, odgovor na terapiju i napredovanje bolesti na osnovu različitih modela (farmakokinetički - FK, farmakodinamički - FD, FK/FD modeli itd.) i simulacija. Regulatorna tela (Evropska agencija za lekove, Uprava za hranu i lekove) podstiču primenu modelovanja i simulacija u svrhu lakšeg donošenja odluka tokom svih faza razvoja lekova. Štaviše, identifikacija faktora koji doprinose varijabilnosti predstavlja osnovu za individualizaciju doze u rutinskoj kliničkoj praksi. Ovaj revijalni rad sumira trenutno znanje u vezi sa primenom farmakometrije u razvoju lekova i kliničkoj praksi sa fokusom na populacionu analizu.
\end{abstract}

Ključne reči: farmakometrija, populaciona analiza, farmakokinetika, farmakokinetičko-farmakodinamičko modelovanje 